\title{
Study of $p-\mathrm{Fe}_{3} \mathrm{O}_{4} / n-(\mathrm{GaAs}, \mathrm{Si})$ Heterostructures: Fabrication and Physical Properties
}

\author{
V. Lisauskas ${ }^{a, *}$, K. ŠliužIenE $\dot{E}^{a, b}$, R. Butkuté $\dot{E}^{a}$, \\ S. Tamulevicius ${ }^{b}$, M. Andrulevicius ${ }^{b}$ And B. Vengalis ${ }^{a}$ \\ ${ }^{a}$ Semiconductor Physics Institute \\ Goštauto 11, LT-01108 Vilnius, Lithuania \\ ${ }^{b}$ Institute of Physical Electronics of Kaunas University of Technology \\ Savanoriu 271, Kaunas, Lithuania
}

\begin{abstract}
We report preparation and investigation of $p-n$ heterostructures based on $\mathrm{Fe}_{3} \mathrm{O}_{4}$ thin films grown on semiconductor $\mathrm{Si}$ and GaAs substrates. $\mathrm{Fe}_{3} \mathrm{O}_{4}$ films with thickness ranging from 60 to $300 \mathrm{~nm}$ were grown at $350 \div 450^{\circ} \mathrm{C}$ using dc magnetron sputtering technique. The measurement of X-ray diffraction and reflection high energy electron diffraction revealed polycrystalline microstructure of thin $\mathrm{Fe}_{3} \mathrm{O}_{4}$ films deposited on both $\mathrm{Si}$ and GaAs substrate. Investigation of surface composition by X-ray photoelectron spectroscopy showed that Fe $2 p$ peak consists of three main peaks, namely, metallic iron $\mathrm{Fe}(0), \mathrm{Fe}(\mathrm{II})$, and $\mathrm{Fe}(\mathrm{III})$. Transport measurements of $\mathrm{Fe}_{3} \mathrm{O}_{4} / n$ - $(\mathrm{Si}$, GaAs) heterostructures demonstrated nonlinear current-voltage $(I-V)$ dependences in the temperature range from $300 \mathrm{~K}$ to $78 \mathrm{~K}$.
\end{abstract}

PACS numbers: 73.40.-c, 73.40.Gk, 81.15.Cd

\section{Introduction}

The next generation spintronics devices combining the advantages of magnetic materials and semiconductors are expected to be non-volatile, fast and capable of simultaneous data storage and consuming less energy. The major challenges for the developing of these devices is the integration of magnetic and semiconductor materials. One of the most suitable candidates for this type of system could be a half-metallic magnetite, $\mathrm{Fe}_{3} \mathrm{O}_{4}$ [1]. The ferrimagnetic $\mathrm{Fe}_{3} \mathrm{O}_{4}$ is an attractive material due to high Curie temperature $\left(T_{\mathrm{C}} \approx 860 \mathrm{~K}\right)$ and high spin polarization (close to $100 \%$ ) at room temperature. $\mathrm{Fe}_{3} \mathrm{O}_{4}$ has a strongly correlated electron

*corresponding author; e-mail: lisa@pfi.lt 
system and undergoes a simultaneous structural and electronic transition at the characteristic Verwey transition temperature $\left(T_{\mathrm{V}} \approx 120 \mathrm{~K}\right)[2]$. Up to now the $p-n$ structures containing $\mathrm{Fe}_{3} \mathrm{O}_{4}$ have rarely been studied. Thus, the challenge would be to synthesize high quality magnetite films on semiconductor substrates such as Si and GaAs.

The goal of this work was preparation and study of diode type heterostructures consisting of $n$-GaAs or $n$-Si substrates with overgrown $p$ - $\mathrm{Fe}_{3} \mathrm{O}_{4}$ films. Special attention was paid to the search of optimal growth conditions, characterization of individual films and heterostructures, and investigation of their transport properties.

\section{Experiment}

Thin $\mathrm{Fe}_{3} \mathrm{O}_{4}$ films with thickness ranging from 60 to $300 \mathrm{~nm}$ were grown in situ at $350 \div 450^{\circ} \mathrm{C}$ by a reactive dc magnetron sputtering on $\mathrm{GaAs}$ and $\mathrm{Si}$ substrates. A metallic iron disk was used as a target. Positioning the substrates in the "off-axis" geometry at different distance from the target enabled us to vary both thickness of the grown films and film composition (Fe to oxygen ratio). The magnetite films were patterned by putting metallic foil mask with a set of opened squares $\left(1 \times 1 \mathrm{~mm}^{2}\right)$ on the substrates prior to film deposition. The film growth was performed in $\mathrm{Ar}: \mathrm{O}_{2}$ gas mixture (30:1) keeping partial oxygen pressure in the vacuum chamber of about $0.16 \mathrm{~Pa}$. After deposition, the films were cooled down slowly to room temperature under the same oxygen pressure conditions.

Microstructure of the films was studied by means of X-ray diffraction (XRD) and reflection high energy electron diffraction (RHEED) techniques. X-ray photoelectron spectroscopy (XPS) was employed to study surface composition of $\mathrm{Fe}_{3} \mathrm{O}_{4}$ films. Transport properties of the films were measured in a wide range of temperature from 78 to $300 \mathrm{~K}$ by applying standard four point-probe method and using dc current of about 10-100 $\mu \mathrm{A}$. The interface resistance and current vs. voltage $(I-V)$ dependences of the heterostructures were measured by applying three point-probe method (with current flowing through the interface between $p$ - and $n$-type materials).

\section{Results and discussion}

The analysis of XRD spectra measured for the $\mathrm{Fe}_{3} \mathrm{O}_{4}$ films, deposited on substrates kept at different distances from the discharge symmetry axis, showed both thickness variation of the grown films and film composition deviation (Fe and oxygen ratio) from the stoichiometric compound. The XRD spectra of the films grown on the substrates kept near the symmetry axis of the discharge (at a distance of about $30 \div 35 \mathrm{~mm}$ ) demonstrated reflexes corresponding to the $\mathrm{Fe}_{3} \mathrm{O}_{4}$ phase and traces of reflexes corresponding to a negligible amount of Fe clusters. Spectra of the films prepared on the substrates positioned at a distance of $45 \mathrm{~mm}$ from the symmetry axis of the discharge exhibited XRD peaks attributed only to 
the stoichiometric $\mathrm{Fe}_{3} \mathrm{O}_{4}$, meanwhile weak reflexes of $\mathrm{Fe}_{2} \mathrm{O}_{3}$ phase appeared in the spectra with increasing the distance up to $60 \mathrm{~mm}$.

Analysis of the $\mathrm{Fe}_{3} \mathrm{O}_{4}$ films surface composition carried out by XPS showed that $\mathrm{Fe} 2 p$ peak consists of three main peaks, namely, metallic iron $\mathrm{Fe}(0), \mathrm{Fe}(\mathrm{II})$, and $\mathrm{Fe}(\mathrm{III})$, accompanied with typical Fe(II) peaks at $715 \mathrm{eV}$ and $728 \mathrm{eV}$ and small $\mathrm{Fe}(\mathrm{III})$ peak at $719 \mathrm{eV}$. After appropriate peak area calculation, it was found that the $\mathrm{Fe} 2 p_{3 / 2}$ peaks ratio of metallic iron $\mathrm{Fe}(0), \mathrm{Fe}(\mathrm{II})$, and $\mathrm{Fe}(\mathrm{III})$ ions in our deposited films is $14.6 \%, 46.4 \%$, and $39.1 \%$, respectively.

Electrical measurements of the prepared $\mathrm{Fe}_{3} \mathrm{O}_{4} / \mathrm{Si}$ and $\mathrm{Fe}_{3} \mathrm{O}_{4} / \mathrm{GaAs}$ heterostructures demonstrated typical semiconductor-like increase in the interface resistance with temperature decreasing down to $78 \mathrm{~K}$. Figure 1 demonstrates current-voltage dependences measured at $T=300 \mathrm{~K}$ and $78 \mathrm{~K}$ for the $\mathrm{Fe}_{3-\delta} \mathrm{O}_{4} / n$-Si heterostructures with three different $\mathrm{Fe}_{3-\delta} \mathrm{O}_{4}$ layers: $\mathrm{Fe}_{3-\delta} \mathrm{O}_{4}$ with small content of $\mathrm{Fe}_{2} \mathrm{O}_{4}$ phase (dotted line), stoichiometric $\mathrm{Fe}_{3} \mathrm{O}_{4}$ (solid line), and stoichiometric $\mathrm{Fe}_{3} \mathrm{O}_{4}$ containing Fe clusters (dashed line). Clearly defined rectifying behaviors have been indicated for the heterostructures both at room temperature and at $T=78 \mathrm{~K}$. It can be seen from Fig. 1 that differential resistance of the heterostructures at zero bias $\left(R_{\mathrm{d}}=\mathrm{d} V / \mathrm{d} I\right)$ increased significantly with cooling down to $T=78 \mathrm{~K}$. In all cases, current through the interface was found to increase steeply with forward bias $(V>0)$ at a certain critical value $V_{\mathrm{d}}$ (diffusion voltage) corresponding to the mismatch between band structures of $p-\mathrm{Fe}_{3-\delta} \mathrm{O}_{4}$ and $n$-type Si.
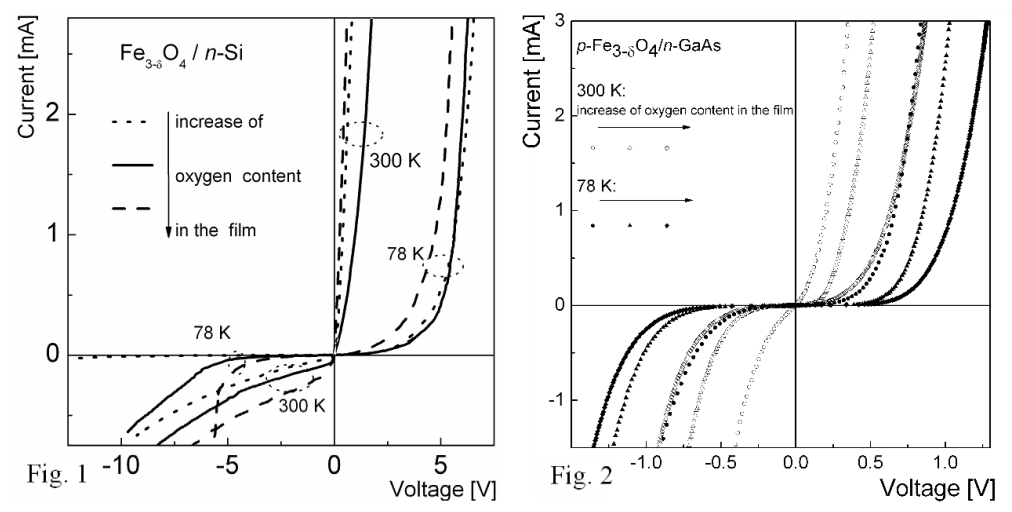

Fig. 1. $I-V$ characteristics measured at $T=300 \mathrm{~K}$ and $78 \mathrm{~K}$ for the heterostructures with different $\mathrm{Fe}_{3-\delta} \mathrm{O}_{4}$ layers: $\mathrm{Fe}_{3-\delta} \mathrm{O}_{4}$ with small content of $\mathrm{Fe}_{2} \mathrm{O}_{4}$ (dotted line), stoichiometric $\mathrm{Fe}_{3} \mathrm{O}_{4}$ (solid line), and $\mathrm{Fe}_{3} \mathrm{O}_{4}$ with Fe clusters (dashed line).

Fig. 2. $I-V$ dependences measured for the $\mathrm{Fe}_{3-\delta} \mathrm{O}_{4} / \mathrm{GaAs}$ heterostructures at $300 \mathrm{~K}$ (open symbols) and $78 \mathrm{~K}$ (filled symbols).

Figure 2 presents the results of transport measurements of similar heterostructures containing different films grown on $n$-type GaAs substrates. It is 
seen from Fig. 2 that influence of oxygen content on the $I-V$ characteristics is different compared to that for the $\mathrm{Fe}_{3-\delta} \mathrm{O}_{4} / \mathrm{Si}$ heterostructures. As a possible reason we point out an interface layer appearing between $\mathrm{Fe}_{3} \mathrm{O}_{4}$ and GaAs during film growth. Tunneling of electrons and holes through this interlayer may result in nonlinear and nearly symmetric $I-V$ curves. Absence of magnetic field influence on electrical properties of the heterostructure shows that this interfacial layer is probably a magnetically "dead" layer.

In conclusion, we have studied the growth, microstructure and transport properties of $\mathrm{Fe}_{3-\delta} \mathrm{O}_{4} / n-(\mathrm{Si}, \mathrm{GaAs})$ heterostructures. The influence of oxygen content in $\mathrm{Fe}_{3-\delta} \mathrm{O}_{4}$ film on the $I-V$ characteristics of the interfaces was demonstrated. The $I-V$ dependences measured for the $\mathrm{Fe}_{3-\delta} \mathrm{O}_{4} / n$-Si heterostructures exhibited strong rectifying behavior both at room temperature and at $T=78 \mathrm{~K}$, meanwhile the transport measurements revealed nonlinear and almost symmetric current vs. voltage curves for the $\mathrm{Fe}_{3-\delta} \mathrm{O}_{4} / n$-GaAs heterostructures.

\section{Acknowledgments}

The authors gratefully acknowledge the financial support of the Lithuanian State Science and Studies Foundation (grant No. T-102/07 and grant No. C-18/2007 project MULTIMA) and EC (Post Doc Grant in the project No. BPD2004-ESF-2.5.0-03-05/0029).

\section{References}

[1] D.C. Kundaliya, S.B. Ogale, L.F. Fu, S.J. Welz, J.S. Higgins, G. Langham, S. Dhar, N.D. Browning, T. Venkatesan, J. Appl. Phys. 99, 08K304 (2006).

[2] M. Ziese, U. Köhler, A. Bollero, R. Höhne, P. Esquinazi, Phys. Rev. B 71, 180406(R) (2005). 